\title{
Streptokinase treatment for femoral artery thrombosis after arterial cardiac catheterisation in infants and children
}

\author{
F Brus, M Witsenburg, W J D Hofhuis, J A Hazelzet, J Hess
}

\begin{abstract}
Data on 205 children who underwent retrograde arterial catheterisation were studied to assess the frequency of femoral artery thrombosis and the safety and efficacy of systemic streptokinase treatment for this complication. In $29(14 \%)$ a transarterial balloon dilatation was performed. In $15(7 \cdot 3 \%)$ patients impaired arterial perfusion due to vascular spasm with or without thrombus formation was seen in the cannulated leg after catheterisation. Despite heparinisation, signs of impaired arterial circulation persisted in nine patients $(4.4 \%$ of the total). In these patients femoral artery thrombosis was strongly suspected. Six $(53 \%)$ of these had undergone a balloon dilatation. Therefore in this study the risk of femoral artery thrombosis developing was 12 times greater after transarterial balloon dilatation than after arterial catheterisation without dilatation $(20.6 \%$ $v 1 \cdot 7 \%$ ). Systemic infusion of streptokinase was started in all patients with femoral artery thrombosis. Arterial perfusion became normal in all patients, though in one this was delayed. Haematological monitoring showed lengthening of the thrombin time and a decrease of the fibrinogen concentration during streptokinase treatment. There were no serious complications.
\end{abstract}

Systemic infusion of streptokinase is a safe and useful treatment in children with persistent femoral artery thrombosis after arterial cardiac catheterisation.

Femoral artery thrombosis is the most common complication of retrograde arterial cardiac catheterisation in children. ${ }^{1-3}$ Catheterisation of infants weighing less than $10 \mathrm{~kg}$ and the growing use of transarterial balloon dilatation procedures increase the frequency of this complication. ${ }^{245}$

In older children surgical thrombectomy has been undertaken with varying success. ${ }^{145}$ Because the risk of extending vascular damage is higher in neonates and infants they are less suitable for surgical intervention. ${ }^{25}$

The systemic use of thrombolytic agents seems to be a safe and effective alternative to surgical treatment. ${ }^{45} \mathrm{We}$ studied a group of children treated with streptokinase because of femoral artery thrombosis after cardiac catheterisation.

\section{Patients and methods}

Between 1 January 1987 and 1 December 1988, retrograde arterial cardiac catheterisation was performed in 205 children. Of these, $29\left(14^{\circ} \%\right)$ children underwent transarterial balloon dilatation. These children received an extra intravenous bolus of heparin $(110 \mathrm{U} / \mathrm{kg})$ during the procedure as well as the heparin solution used routinely in every child to flush catheters. Thirty four $(16 \%)$ children weighed less than $10 \mathrm{~kg}$.

Before and after catheterisation the arterial perfusion of both legs was assessed by examination of arterial pulses, blood pressure, colour, and temperature. Patients with absent or reduced arterial pulsations, substantially decreased blood pressure, pallor, and diminished skin temperature of the cannulated leg shortly after the end of the procedure were considered to have impaired arterial perfusion due to arterial spasm with or without thrombus formation. We studied the data on these patients.

In all these patients heparin was administered for different times and monitored by the activated partial thromboplastin time. In patients with persistent signs of impaired arterial circulation despite heparinisation a tentative diagnosis of arterial thrombosis was made and streptokinase was used for systemic thrombolytic treatment.

The distribution of age and weight (mean (SD)) and also the interval (mean (SD)) between the end of the catheterisation and the start of streptokinase treatment were determined. The duration of treatment (mean (SD)) was also assessed.

Before and during streptokinase treatment prothrombin time, activated partial thromboplastin time, and plasma fibrinogen concentrations were recorded in all patients; in some patients the thrombin time was also measured. Two hours after the end of streptokinase treatment heparinisation was restarted in all patients to prevent re-thrombosis after successful treatment or persisting thrombus formation after treatment failure. This was continued for 12 hours.

\section{Results}

Shortly after the end of the catheterisation 15 $(7 \cdot 3 \%)$ of 205 patients showed impaired arterial perfusion of the cannulated leg. In six $(40 \%)$ of these the arterial circulation became normal during systemic heparin treatment. Despite continued heparinisation arterial perfusion remained impaired in the remaining nine patients $(60 \%, 4.4 \%$ of 205 patients) 
Table 1 Patients with femoral artery thrombosis treated by systemic infusion of streptokinase

\begin{tabular}{|c|c|c|c|c|c|}
\hline Patient No & Age (yr) & Weight (kg) & Diagnosis & $\begin{array}{l}\text { Transarterial } \\
\text { balloon dilatation }\end{array}$ & $\begin{array}{l}\text { Interval between end of } \\
\text { catheterisation and start } \\
\text { of streptokinase }(h)\end{array}$ \\
\hline $\begin{array}{l}1 \\
2 \\
3 \\
4 \\
5 \\
6 \\
7 \\
8 \\
9\end{array}$ & $\begin{array}{l}5 \cdot 4 \\
1 \cdot 6 \\
1 \cdot 2 \\
9 \cdot 6 \\
0 \cdot 4 \\
11 \cdot 0 \\
0 \cdot 08 \\
6 \cdot 6 \\
0 \cdot 02\end{array}$ & $\begin{array}{r}17 \cdot 7 \\
8 \cdot 8 \\
7 \cdot 0 \\
22 \cdot 4 \\
6 \cdot 6 \\
25 \cdot 4 \\
5 \cdot 2 \\
17 \cdot 2 \\
3 \cdot 2\end{array}$ & $\begin{array}{l}\text { Aortic recoarctation } \\
\text { TA } \\
\text { VSD } \\
\text { AVS } \\
\text { AVS } \\
\text { AVS } \\
\text { AVS } \\
\text { MPPS } \\
\text { PA, VSD }\end{array}$ & $\begin{array}{l}+ \\
- \\
- \\
+ \\
+ \\
+ \\
+ \\
+ \\
-\end{array}$ & $\begin{array}{r}144 \\
51 \\
48 \\
48 \\
122 \\
24 \\
24 \\
19 \\
56\end{array}$ \\
\hline $\operatorname{Mean}(\mathrm{SD})$ & $3 \cdot 9(4 \cdot 3)$ & $12 \cdot 6(8 \cdot 1)$ & & & $59.7(44.0)$ \\
\hline
\end{tabular}

TA, tricuspid valve atresia; VSD, ventricular septal defect; AVS, aortic valve stenosis; MPPS, multiple peripheral pulmonary stenoses; PA, pulmonary atresia.

Table 2 Systemic streptokinase infusion in nine patients with femoral artery thrombosis after retrograde arterial catheterisation

\begin{tabular}{lllll}
\hline Patient No & $\begin{array}{l}\text { Loading dose in } \\
\text { 30 min }(U / \mathrm{kg})\end{array}$ & $\begin{array}{l}\text { Infusion dose } \\
(\boldsymbol{U} / \mathrm{kg} / \mathrm{h})\end{array}$ & Duration $(\boldsymbol{h})$ & Complications \\
\hline 1 & 1000 & 1000 & 29 & None \\
2 & 1000 & 1000 & 7 & None \\
3 & 1000 & 1000 & 12 & None \\
4 & 2000 & 1000 & 58 & Haematoma groin \\
5 & 3000 & 1500 & 8 & None \\
6 & 3000 & 1000 & 24 & Bleeding groin \\
7 & 3000 & 1000 & $24^{\star}$ & None \\
8 & 3000 & 1000 & 120 & None \\
9 & 3000 & 1000 & 72 & No effect \\
\hline
\end{tabular}

*Because of an inadequate result after 24 hours of treatment the dose of streptokinase was increased after another loading dose. This was successful after 45 hours.

$59 \cdot 7(44 \cdot 0)$ hours (range 19-144 hours) after the procedure and femoral artery thrombosis without vascular spasm was strongly suspected (table 1). Six of these nine patients had undergone a transarterial balloon dilatation. The median weight of these children was 12.6 $(8 \cdot 1) \mathrm{kg}$ (range $3 \cdot 2-25 \cdot 4 \mathrm{~kg}$ ); five of them weighed less than $10 \mathrm{~kg}$. The median age was 3.9 (4.3) years (range 9 days-11 years).

During systemic streptokinase treatment (table 2) arterial perfusion became normal in eight $\left(89^{\circ}\right)$ of nine patients after 7-120 hours (mean 39.6 (38.9) hours). Because of persisting impaired perfusion after 24 hours of treatment the streptokinase dose was increased in one patient (patient 7, table 2) after another loading dose. This resulted in normal arterial circulation after 45 hours. In the youngest patient (patient 9, table 2) absence of pulses and low systolic blood pressure persisted despite laboratory signs of adequate fibrinolysis. After 72 hours thrombolytic treatment in this patient was stopped. However, femoral artery perfusion was normal 5 days after the end of streptokinase treatment. There were no signs

Table 3 Thrombin time and plasma fibrinogen concentration before and during streptokinase treatment

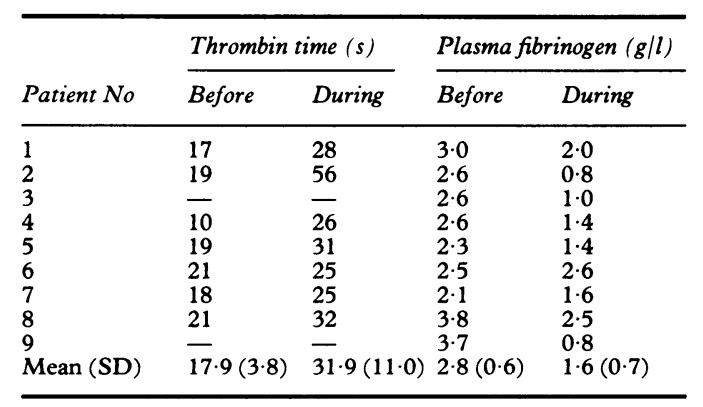

of re-thrombosis at follow up after 3-20 months in any patient.

During streptokinase treatment the prothrombin time and partial thromboplastin time did not change. The thrombin time increased (from $17.9(3.8) \mathrm{s}$ to $31.9(11.0) \mathrm{s}$, mean relative increase of $0.85(0.61)$ and the plasma fibrinogen concentration decreased (from $2 \cdot 8$ $(0.6) \mathrm{g} / 1$ to $1.6(0.7) \mathrm{g} / \mathrm{l}$, mean relative decrease of $0.42(0.24))$. The fibrinogen concentration did not change in patient 6 , in whom streptokinase treatment resulted in a normal circulation after 45 hours (table 3 ).

There was no substantial bleeding during or after streptokinase treatment except for minimal bleeding at the arterial entry site that could be stopped by groin compression. No allergic reactions were seen.

\section{Discussion}

Obstruction of the femoral artery by thrombus is a complication of retrograde arterial catheterisation in children. This has been confirmed by arteriography in some studies. ${ }^{1-3}$ Vascular spasm only contributes to femoral artery obstruction shortly after the end of the procedure. ${ }^{2}$ Spasm is unlikely to persist for more than a few hours. ${ }^{2}$ In this study we regarded persistent signs of impaired arterial circulation despite heparinisation as being the result of thrombus formation without vascular spasm.

Femoral artery thrombosis is the most common complication after retrograde arterial catheterisation in children ${ }^{1-3}$-it was reported in $3-5^{\circ}$ of patients despite increased experience with catheterisation techniques, better materials, and systemic treatment with heparin. ${ }^{145}$ The result in our study $(4.4 \%)$ 
accords with these earlier results. Furthermore, femoral artery thrombosis was 12 times more common after retrograde transarterial balloon dilatation than after arterial catheterisation alone $(20.6 \% v 1.7 \%)$. The larger diameter of the balloon catheters and the irregular surface of the balloon may contribute to increased intimal damage and vascular spasm. ${ }^{46}$ This is an important finding because the number of retrograde transarterial balloon dilatations has greatly increased in past years. ${ }^{6-8}$ Young children, especially those weighing less than $10 \mathrm{~kg}$, have a higher frequency of femoral artery thrombosis after retrograde arterial catheterisation than older children and adults. ${ }^{245} \mathrm{We}$ found femoral artery thrombosis in $14 \cdot 7^{\circ}$ of children weighing $<10 \mathrm{~kg}$ and in $2 \cdot 3^{\circ}{ }_{0}$ of children weighing $>10 \mathrm{~kg}$. Although tissue ischaemia after femoral artery thrombosis is rare, disturbance of growth and function of the leg can be impressive. ${ }^{249}$ Therefore, it is very important to evaluate arterial perfusion of both legs after each retrograde arterial catheterisation. Absent or reduced arterial pulsations, substantially decreased blood pressure, pallor, and diminished skin temperature of the cannulated leg after the end of the procedure are reliable criteria for femoral artery obstruction. $^{245}$

Persistence of impaired perfusion of the femoral artery indicates that treatment is needed. Surgical intervention, especially in younger children, is associated with a substantial risk of extending vascular damage. ${ }^{25}$ In older children it has been undertaken with varying success. ${ }^{145}$ The use of thrombolytic agents seems to be a preferable alternative. ${ }^{45}$ These agents act directly or indirectly as plasminogen activators. They activate plasminogen, an inactive proteolytic enzyme in plasma, to produce the fibrinolytic enzyme plasmin. ${ }^{10}$

We treated our patients with streptokinase because this is the agent that has been most used in children for this indication. Streptokinase is a protein obtained from group $C \beta$ haemolytic streptococci. ${ }^{510}$ In our study femoral artery thrombosis occurred in nine patients after retrograde arterial catheterisation despite continued heparinisation. These patients were treated with systemic infusion of streptokinase. We did not perform local arterial infusion because this requires cannulation of another artery with the attendant risk of endothelial damage and possible formation of a new thrombus. ${ }^{11}$

In eight $(89 \%)$ of nine patients systemic streptokinase treatment was successful. This accords with the results of two recently published studies. ${ }^{45}$ The mean duration of treatment was greater in our patients than in these other studies ( $37.9 v 13.0$ hours). Older thrombi are more resistant to fibrinolysis. Peripheral arterial thromboses that are $>24$ hours old need longer treatment with streptokinase. ${ }^{510}$ In our study the interval between the end of catheterisation and start of streptokinase treatment was not clearly related to how long treatment was needed. Despite laboratory signs of adequate fibrinolysis, streptokinase treatment was not immediately successful in one patient $(11 \%)$ (the youngest in our series (9 days old)). Femoral artery perfusion was normal after 5 days, however. Recanalisation after spontaneous resolution of the thrombus is highly unlikely to have occurred in such a short period. Failure of thrombolytic treatment in neonates may be attributed to the lower concentrations of plasminogen or because the functional activity of plasminogen is less than the concentrations of plasminogen inhibitors (especially $\alpha_{2}$ antiplasmin). ${ }^{12-14}$ Sometimes the use of massive amounts of thrombolytic agents may be successful in these cases. ${ }^{14}$ Activation of plasminogen by thrombolytic agents can result in haematological changes (particularly an increase of thrombin time and a decrease in plasma fibrinogen as well as an increase in plasma fibrin degradation products). ${ }^{10}{ }^{15}$ Monitoring of prothrombin time, partial thromboplastin time, thrombin time, plasma fibrinogen, and fibrin degradation products is a useful guide to adjusting thrombolytic treatment to avoid systemic bleeding complications. ${ }^{51015}$ In our patients there was no lengthening of prothrombin time and partial thromboplastin time, but the thrombin time increased and there was a moderate decrease in plasma fibrinogen concentrations-both signs of fibrinolysis (table 3 ).

Bleeding is the most hazardous complication of systemic thrombolytic treatment. We saw no serious bleeding complications in our study. Bleeding from the arterial entry site is the most common complication-particularly in patients undergoing balloon dilatation procedures. This complication was seen in one of our patients. Local compression will usually stop the bleeding. ${ }^{45}$

During thrombolytic treatment invasive procedures must be avoided. ${ }^{10}$ Contraindications to thrombolytic treatment are the presence of or predisposition to intracranial haemorrhage, active internal bleeding (for example, gastrointestinal), recent major surgery (within 10 days), and a pre-existing bleeding tendency. ${ }^{15}$ If serious bleeding develops thrombolysis must be stopped immediately and coagulation changes reversed by the use of fresh frozen plasma and cryoprecipitate. ${ }^{10}$

To avoid re-thrombosis after successful thrombolytic treatment or when thrombus formation persisted after treatment failure we treated our patients with heparin. The optimal anti-thrombotic regimen to prevent these problems still needs to be established. Heparin and/or aspirin have been recommended. ${ }^{16}$ Like other investigators we did not encounter rethrombosis in our patients. ${ }^{45}$

Treatment with streptokinase (a bacterial problem) is occasionally associated with an allergic reaction (rash, fever, nausea, a syndrome resembling serum sickness, and anaphylactic shock) especially in patients exposed to a recent streptococcal infection or streptokinase treatment. ${ }^{10}$ Urokinase, a human product, is non-antigenic and can be used instead of streptokinase. ${ }^{10}$ There were no allergic reactions in our patients.

The doses that we used and those used by others in children were not established by 
pharmacological investigations but were estimated from experience in adult patients. These doses were safe and effective but we do not know whether they are pharmacologically optimal.

In our study group the early use of streptokinase in the treatment of femoral artery thrombosis after percutaneous retrograde catheterisation in infants seemed to be beneficial. Because proof of the efficacy of treatment with streptokinase cannot be drawn from this study we recommend that a randomised, controlled study should be undertaken.

1 Stanger P, Heyman MA, Tarnoff H, Hoffman JIE, Rudolf AM. Complication of cardiac catheterization of neonates, infants and children. A three-year study. Circulation 1974;50:595-608.

2 Girod DA, Hurwitz RA, Caldwell RL. Heparinization for prevention of thrombosis following pediatric percutaneous arterial catheterization. Pediatr Cardiol 1982;3: 175-80.

3 Freed MD, Keane JF, Rosenthal A. The use of heparinization to prevent arterial thrombosis after percutaneous cardiac catheterization in children. Circulation 1974; 50:565-9.

4 Wessel DL, Keane JF, Fellows KE, Robichaud H, Lock JE. Fibrinolytic therapy for femoral arterial thrombosis afte cardiac catheterization in infants and children. $A m J$ Cardiol 1986;58:347-51.

5 Ino T, Benson LN, Freedom RM, Barker GA, Aipursky A, Rowe RD. Thrombolytic therapy for femoral artery thrombosis after pediatric cardiac catheterization. $A m$ Heart J 1988;115:633-9.

6 Kan JS, White RI, Mitchel SE, Gardner TJ. Percutaneous balloon valvuloplasty: a new method for treating congenital pulmonary valve stenosis. $N$ Engl J Med 1982;307: 540-2.

7 Perry SB, Keane JF, Lock JE. Interventional catheterization in pediatric congenital and acquired heart disease. $\mathrm{Am}$ Cardiol 1988;61:109G-17G.

8 Hess J, Mooyaart EL, Busch HJ, Bergstra A, Landsman MLJ. Percutaneous transluminal balloon angioplasty in 1986;55:459-61.

9 Mansfield PB, Gazzaniga AB, Litwin SB. Management of arterial injuries related to cardiac catheterization in children and young adults. Circulation 1970;42:501-2.

10 Marder VJ, Sherry S. Thrombolytic therapy: current status (first of two parts) N Engl J Med 1988;318:1512-20.

11 Eskridge JM, Becker GJ, Rabe FE, et al. Catheter-related thrombosis and fibrinolytic therapy. Radiology 1983; 149:429-32.

12 Estelles A, Aznar J, Gilabert J, Parilla JJ. Dysfunctional plasminogen in full-term newborn. Pediatr Res 1980; 14:1180-5.

13 Ekelund J, Hedner U, Nilsson IM. Fibrinolysis in newborns. Acta Paediatr Scand 1970;59:33-43.

14 Delaplane D, Scott JP, Riggs TW, Silverman BL, Hunt CE. Urokinase therapy for a catheter-related right atrial Urokinase therapy for a catheter-relat

15 Marder VJ, Sherry S. To (second of two parts) N Engl J Med 1988;318:1585-95.

16 Chesebro JH, Fuster V. Antithrombotic therapy for acute myocardial infarction: mechanisms and prevention of deep venous, left ventricular and coronary artery thromboembolism. Circulation 1986;74(suppl III):III-1-10. 